\section{Esophageal fully covered self-expanding metal stent for combined treatment of an aortoesophageal fistula}

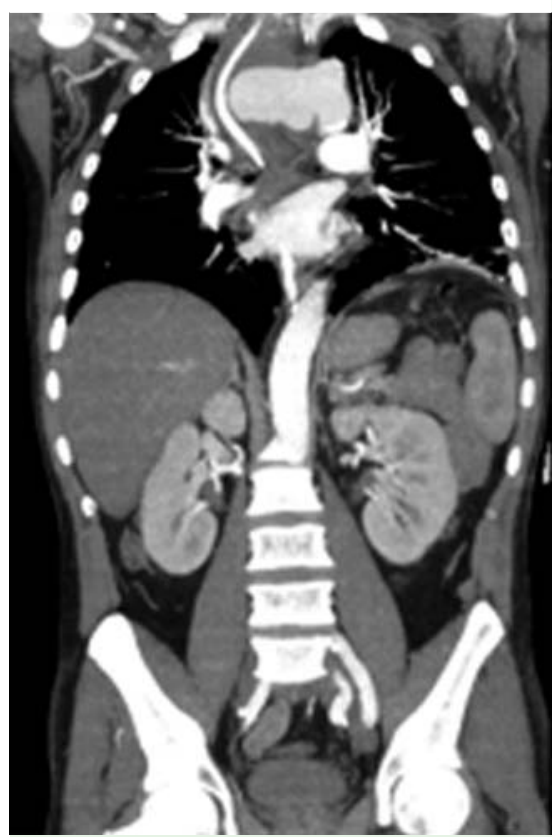

Fig. 1 Computed tomography (CT) scan showing a thoracic aortic pseudoaneurysm causing a mass effect on the esophagus.

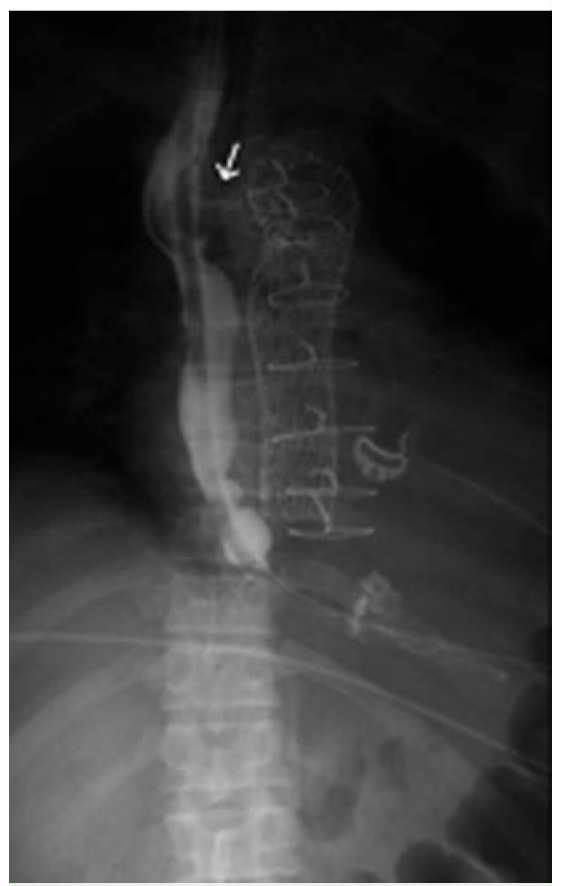

Fig. 2 Gastrografin esophagram showing discontinuity in the medial aspect of the esophagus (arrow) at the level of the aortic arch.
We report on a 63-year-old man with a history of coronary artery bypass in 1995 who presented with massive hematemesis and hemodynamic instability. A computed tomography (CT) scan revealed a thoracic aortic pseudoaneurysm causing a mass effect on the esophagus ( $\bullet$ Fig. 1) and rupture of the aorta immediately after the origin of the left subclavian artery, with the suspicion of an aortoesophageal fistula.

Endovascular aortic treatment was undertaken with a carotid-subclavian bypass using a polytetrafluoroethylene stent. A Gastrografin esophagram 4 days after admission revealed a discontinuity in the medial aspect of the esophagus at the level of the aortic arch ( $\bullet$ Fig.2). An upper gastrointestinal endoscopy performed the following day confirmed a 4-cm long esophageal rupture $20 \mathrm{~cm}$ from the incisors ( Fig.3). A fully covered, $110-\mathrm{mm} \times$ 20-mm, Nitinol self-expanding metal stent (Hanarostent M.I.Tech Co. Inc., Seoul, South Korea) was placed under direct visualization to isolate the esophageal perforation and a nasogastric tube was subsequently placed.

The patient was initially kept on enteral feeding, later progressing to an oral diet. Twenty weeks after the placement of the esophageal stent, the patient remains alive, with no evidence of mediastinitis, aortic stent-graft infection or new episodes of gastrointestinal bleeding, with the esophageal stent being correctly placed ( $\bullet$ Fig.4).

Aortoesophageal fistulas are a rare cause of massive upper gastrointestinal bleeding; one of the main causes is erosion of the esophageal wall by thoracic aortic aneurysms [1]. Endovascular aortic repair enables aortic bleeding to be rapidly controlled [2]; however, it does not repair the esophagus, so leaves the risk of mediastinitis and aortic graft contamination.

Previous reports have considered surgical repair of the esophageal lesion once the patient's condition has been stabilized [3], but secondary esophageal reconstruc-

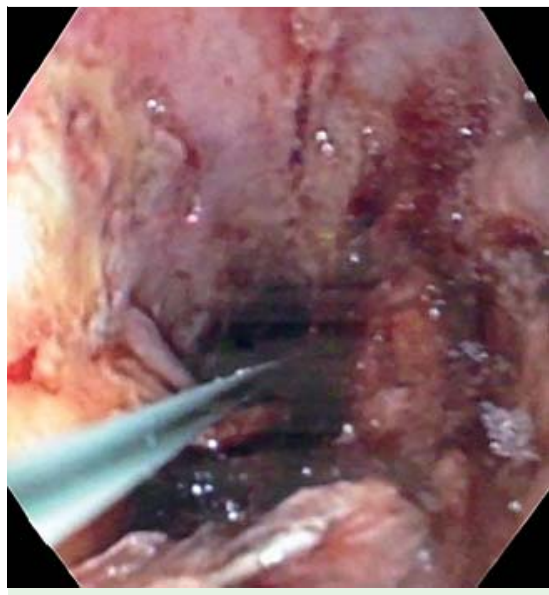

Fig.3 Upper gastrointestinal endoscopy showing a 4-cm long esophageal rupture $20 \mathrm{~cm}$ from the incisors, with no evidence of spontaneous purulent drainage.

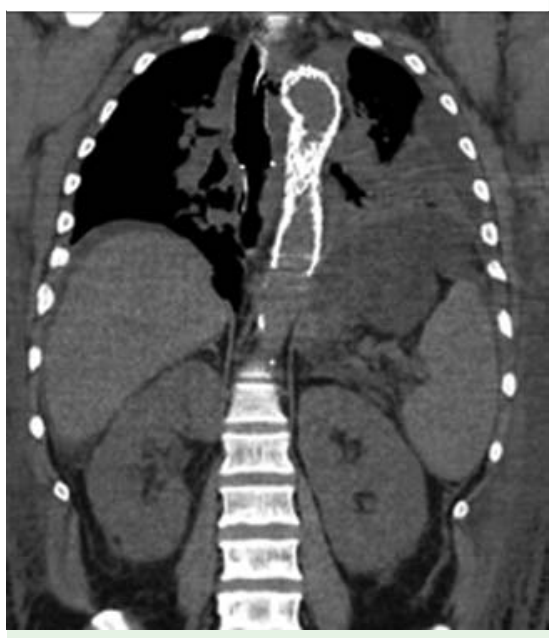

Fig. 4 Computed tomography (CT) scan showing the correctly placed esophageal stent.

tion can cause significant surgical trauma. Esophageal stents are universally used to treat esophageal perforations [4]. In selected cases, they may be a less invasive and equally effective alternative to surgical repair, bypassing the defect to allow it to heal, while allowing oral feeding to be continued.

Endoscopy_UCTN_Code_TTT_1AO_2AI

Competing interests: None

\section{Eduardo Rodrigues-Pinto, Pedro Pereira, Guilherme Macedo}

Gastroenterology Department, Centro Hospitalar São João, Porto 


\section{References}

1 Hollander JE, Quick G. Aortoesophageal fistula: a comprehensive review of the literature. Am J Med 1991; 91: 279-287

2 Prokakis C, Koletsis E, Apostolakis E et al. Aortoesophageal fistulas due to thoracic aorta aneurysm: surgical versus endovascular repair. Is there a role for combined aortic management? Med Sci Monit 2008; 14: RA48RA54

3 Topel I, Stehr A, Steinbauer MG et al. Surgical strategy in aortoesophageal fistulae: endovascular stentgrafts and in situ repair of the aorta with cryopreserved homografts. Ann Surg 2007; 246: 853-859
4 Sharma P, Kozarek R. Practice Parameters Committee of American College of Gastroenterology. Role of esophageal stents in benign and malignant diseases. Am J Gastroenterol 2010; 105: 258-273

\section{Bibliography}

Dol http://dx.doi.org/

10.1055/s-0034-1391256

Endoscopy 2015; 47: E73-E74

(c) Georg Thieme Verlag KG

Stuttgart · New York

ISSN 0013-726X

\section{Corresponding author}

Eduardo Rodrigues-Pinto, MD

Gastroenterology Department

Centro Hospitalar São João

Al. Prof. Hernâni Monteiro 4200-319 Porto

Portugal

Fax: +351-22-5513601

edu.gil.pinto@gmail.com 